\title{
Descrevendo a Corporeidade: implicações educativas a partir da ginga do brasileiro no futebol e na dança
}

\author{
Pierre Normando Gomes-da-Silva \\ Departamento de Educação Física da Universidade Federal da Paraíba, João Pessoa - PB - Brasil \\ pierrenormandogomesdasilva@gmail.com \\ Djavan Antério \\ Departamento de Educação Física da Universidade Federal da Paraíba, João Pessoa - PB - Brasil \\ djavananterio@gmail.com \\ Guilherme Barbosa Schulze \\ Departamento de Artes Cênicas da Universidade Federal da Paraíba, João Pessoa - PB - Brasil \\ guilherme.schulze@gmail.com \\ Rodrigo Wanderley de Sousa Cruz \\ Universidade Federal da Paraíba, João Pessoa - PB - Brasil \\ rodrigosousacruz@gmail.com
}

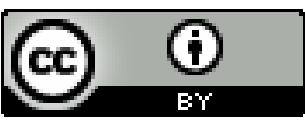

EDUCAÇÃO: Teoria e Prática, Rio Claro, SP, Brasil - elSSN: 1981-8106

Está licenciada sob Licença Creative Common

\section{Resumo}

O presente estudo descreve a corporeidade, a partir de seu signo, a ginga. Ginga como modo perceptivo e expressivo do sujeito cultural relacionar-se com o entorno brasileiro. Trata-se de uma pesquisa descritiva, de abordagem qualitativa, do tipo documental, cuja técnica de coleta se deu por meio de recortes fotográficos (frame a frame) extraídos de duas situações videográficas distintas: drible no futebol e mandinga na dança. Caracterizou-se como questão norteadora do estudo: Quais as implicações educativas decorrentes da ginga brasileira no futebol e na dança? Os dois gestos descritos foram: no futebol, o drible de Robinho (Brasil x Equador, Maracanã/RJ, 2007) e na dança, uma performance de Antônio Nóbrega no espetáculo Lunário Perpétuo (2003). A análise do movimento foi dada a partir da labanálise (LMA), com seus fatores de movimento (tempo, espaço, peso e fluxo). Os resultados evidenciam que o gingado brasileiro pode ser desdobrado em implicações pedagógicas em termos de uma educação sensorial e multicultural.

Palavras-chave: Educação. Corporeidade. Movimento 


\title{
Describing the Corporeality: educational implications from the swing of brazilian football and dance
}

\begin{abstract}
This study describes the corporeality from its sign, the swing. Swing as the perceptive and expressive way of the cultural subject to relate to the Brazilian context. It's about a descriptive research, with qualitative methodology and documentary type, which tecnic of data collect happened from photographics dippings (frame to frame) extracted from two different videographic situations: the dribble of football and the movement of dance. The leading question of the study is characterized by: which are the educative implications that come from the Brazilian swing at football and on the dance? The two gestures described were: at football the Robinho's dribble (Brazil x Ecuador, Maracanã/RJ, 2007) and on the dance, a performance analysis of the movement were given by Laban Movement Analysis (LMA), with its movement factors (time, space, weight and flow). The results show that the Brazilian swing can be deployed in pedagogical implications for sensory and multicultural education.
\end{abstract}

Keywords: Education. Corporeality. Movement.

\section{Describiendo la Corporeidad: implicaciones educativas a partir de la ginga* del brasileño en el fútbol y en la danza}

\section{Resumen}

El presente estudio describe la corporeidad, a partir de su signo, la ginga. Ginga como modo perceptivo y expresivo del sujeto cultural de relacionarse con el entorno brasileño. Se trata de una investigación descriptiva, de abordaje cualitativo, de tipo documental, cuya técnica de recolecta de datos se dio por medio de recortes fotográficos (cuadro a cuadro) extraídos de dos situaciones videográficas distintas: drible en el fútbol y el hechizo en la danza. Se caracterizó como cuestión guía del estudio: ¿Cuáles son las implicaciones educativas derivadas de la ginga brasileña en el fútbol y en la danza? Los dos gestos descritos fueron: en el fútbol, el drible de Robinho (Brasil x Ecuador, Maracanã/RJ, 2007) y en la danza, una performance de Antônio Nóbrega en el espectáculo Lunário Perpétuo (2003). El análisis del movimiento se dio a partir del análisis del movimiento según Laban (LMA), con sus factores de movimiento (tiempo, espacio, peso y flujo). Los resultados evidencian que el gingado brasileño puede desdoblarse en implicaciones pedagógicas en términos de una educación sensorial y multicultural.

Palabras clave: Educación. Corporeidad. Movimiento.

* en portugués: ginga significa el balance, la cadencia, el meneo del cuerpo de un lado para el otro; el ritmo con vigor, fuerza y energía. 


\section{Introdução}

Em meio ao clima futebolístico que toma conta do ambiente nacional, sobretudo pela recente Copa das Confederações (2013) e a iminente Copa do Mundo (2014), momento em que a seleção brasileira busca o hexacampeonato (1958, 1962, 1994, 2002), iniciamos este artigo ratificando nossa hipótese de que o futebol, bem como a dança, produzidos no país, constituem uma vigorosa expressão da cultura brasileira. Desenvolvemos essa ideia a partir de Freyre (1947, p.51), que afirmava ser o futebol "uma verdadeira instituição brasileira, por ter tornado possível a sublimação de vários daqueles elementos irracionais de nossa formação social e de cultura". E a dança, como o movimento típico das manifestações folclóricas brasileiras, tais como: congados, reisados, batuques, folias, bumba-meu-boi, devoções, comemorações cívicas. Ou melhor, a dança é o movimento próprio da "cultura da festa", marca característica do povo brasileiro (MONTES, 1998).

Partindo desse pressuposto de que o futebol e a dança estão inseridos e são marcantes na cultura brasileira, cumpre-nos esclarecer nossa compreensão de movimento corporal como constituinte da corporeidade, tendência geral dos gestos humanos no espaço. Os movimentos não são concebidos como instrumentos do pensar ou expressão do sentir, mas como configuração do ser em envolvimento com o seu mundo. Assim, a corporeidade se constitui e reconstitui-se nos modos de mover-se no mundo, individual ou comunitário. São os movimentos que estabelecem a interação com o entorno naturalhistórico-cultural.

Corporeidade, assim, está dada nas circunstâncias, não está num movimento isolado, mas, sim, no ambiente configurado pelos gestos no mundo. A corporeidade é a forma com que movimentos são produzidos em relação aos outros sujeitos, à natureza, aos objetos ou a si mesmo. É o ambiente de comunicação entre $o$ eu e o mundo, no qual todas as ações (distraídas ou habituais) e inações adquirem sentido (GOMES-DA-SILVA, 2011a). Daí entendermos o movimento humano como desvelamento do ser no tempo, que é o horizonte da espacialidade vivida, ou seja, descrevemos o sentido do movimento como modo do homem estar no mundo junto com outros. Portanto, encaramos o movimento 
como um fenômeno comunicativo que se constitui e reconstitui historicamente na existencialidade cotidiana (GOMES-DA-SILVA, 2012).

Entendemos que $\mathrm{o}$ ato de movimentar-se produz sentido porque expressa a intersubjetividade tanto individual quanto coletiva. A corporeidade é a tendência dos gestos criada pela experiência do corpo ao dirigir-se à circunvizinhança. Essa trajetória descrita pelos gestos no espaço, entre o eu e o mundo, expressam certa maneira de ser no mundo. Para a investigação da corporeidade, o que temos, em termos visíveis, é o corpo movimentando-se no espaço durante certo tempo, mas, diferente dos objetos, o movimento humano revela a experiência vivida, a sensibilidade de uma época e a expressividade de um povo (GOMES-DA-SILVA; GOMES, 2010).

A corporeidade, ou contorno espacial dos movimentos, vai se tornando visível nas tomadas de posições efetivas e na prática de percepção do sujeito vivo em face do mundo, porque são nessas atitudes que ele configura o entorno: animando alguns movimentos e adormecendo outros. Nesse sentido, apostamos que os brasileiros, em sua multiplicidade social e heterogeneidade étnica, estão impregnados profundamente, em seu fazer e sentir, por um movimento característico, a ginga. A ginga fica evidenciada no futebol, especialmente nos dribles, e nas mandingas das danças folclóricas. Com isso não estamos buscando no universo desconcertante da cultura brasileira encontrar uma autenticidade, uma propriedade brasileira, tentação dos folcloristas, mas falar de um lugar comum, presente e marcante nesse difusionismo cultural, o gingado brasileiro. Toledo afirma que:

\footnotetext{
No brasileiro, o ponto de equilíbrio, como ninguém ignora, está na cintura. Um brasileiro, no meio da multidão multinacional, será reconhecido por um certo jeito de rolar a cintura. A plasticidade da cintura escoa para as pernas e pode resultar em força e originalidade no percurso que vai até a ponta dos pés (TOLEDO, 1998, p. 174).
}

Sendo assim, resolvemos descrever a corporeidade, no caso brasileiro, a partir das ações corporais como o drible no futebol e a mandinga na dança, como aqueles que demarcam identidades e pertencimentos, significam exuberâncias e comunicam intenções. Portanto, é o movimentar-se do sujeito no mundo, produzindo e comunicando cognições e afetos, que concretiza e dinamiza as culturas. O drible no futebol e a mandinga na dança folclórica/popular não emergem simplesmente da necessidade do jogador ou dançarino, mas são respostas criadas, mesmo que inconscientes ou culturalmente construídas, às 
situações concretas nas quais os sujeitos se encontram e no ambiente cultural que convivem.

O movimento do dançarino, em nosso caso a mandinga, tem como principal objetivo o de transformar a percepção do espectador, seduzi-lo (GIL, 2009). Já o drible no futebol objetiva desvencilhar-se do adversário por meio de uma ação ludibriadora, mantendo a posse da bola rumo ao campo adversário para enfim marcar o gol (FRISSELLI; MANTOVANI, 1999). A performance de um dançarino torna-se mais interessante e espetacular de acordo com o modo como ele lida com forças que se opõem, tal como o jogador no futebol. As forças opostas no futebol materializam-se no adversário, nos limites espaciais do campo, nas regras específicas do esporte, e na própria habilidade necessária para conduzir a bola. No caso da dança, essas forças tendem a ser menos visíveis, o dançarino lida com as limitações de sua habilidade ou técnica, assim como com a gravidade para apresentar sua performance. Trabalha com o universo da sua imaginação e a de seu público onde uma eventual bola ou o gol podem estar presentes como elementos imaginados. Por exemplo, o espetáculo de dança do Grupo Ximbira (SP, 07/2012), com direção de Edson Lima, dentre tantos outros grupos, que construiu sua coreografia inspirada em cenas do futebol.

Por isso, afirmamos, o drible e a mandinga são signos da corporeidade, porque remetem à malícia, revelam o gingado como uma forma de resistência escrava decorrente de um simbolismo polissêmico "dos ritos holísticos, em que o sagrado, o lúdico e o guerreiro estão fortemente imbricados" (SODRÉ, 2002, p. 86). A ginga, como uma marca, do brasileiro se mover, não é a defesa de uma peculiaridade corporal, porque essa seria uma investigação árdua e com resultados facilmente contestáveis. Mas como um movimento gestado nas rodas cantadas e nos campinhos de várzea, nas brincadeiras de rua e nas festas populares, em território brasileiro. A partir de Cascudo (1976), entendemos a ginga como um gesto que é anterior a palavra, portanto não Ihe é complementar, mas uma provocação. Um manejo corporal característico, imbuído de significados, intencionalidades, anseios e tradição. O gingado é uma forma de ser, de portar-se, de ocupar o espaço-tempo. Na ginga há padrões rítmicos dos africanos, a astúcia, bem como a força de seus corpos energéticos; há, também, a alegria e o espírito guerreiro dos indígenas; por fim, temos a parcela ibérica, através de suas tradicionais danças (RIBEIRO, 1995). 
A ginga está visivelmente presente no futebol, em especial no drible, e nas coreografias das danças da cultura popular. É pela ginga que o jogador ou dançarino, vale também para o capoeirista, situa-se no espaço e habita o tempo, movendo-se em qualquer direção, plano ou nível. É pela ginga que o jogador, em nosso caso Robinho, ou o cantorbrincante, Antônio Nóbrega, entra ou sai da jogada; sobe ou desce do palco; ataca ou defende; gira ou salta. Enfim, a ginga possibilita ao brincante uma visão ampla do jogo, por meio dela seduz, seja o adversário ou o público.

Sendo assim, é possível pensar o movimento da ginga brasileira em termos de representação cultural e implicação educativa. Partimos da premissa de que o processo educativo não se dá de um cérebro a outro, mas de um corpo ao outro, por meio dos gestos, das falas, das emoções, arrazoamentos, sentimentos, resistências e histórias de vida. Por entendermos as práticas corporais, em nosso caso a ginga nos dribles e mandingas, como signos da corporeidade, portanto, com desdobramentos educativos, definimos nossa questão-problema: Quais as implicações educativas decorrentes da ginga brasileira no futebol e na dança?

\section{Trajeto Metodológico}

A pesquisa em questão caracteriza-se como descritiva, de abordagem qualitativa, do tipo documental, cuja técnica de coleta se deu por meio de recortes fotográficos (frame to frame) extraídos de duas situações videográficas distintas: drible no futebol; e performance coreográfica na dança. A técnica frame-to-frame refere-se à fragmentação em quadros de um trecho de uma película ou vídeo com o objetivo de examinar detalhadamente a ação corporal do sujeito analisado. No quadro a quadro há a possibilidade de um olhar minucioso no que se refere à gestualidade corporal, ou às especificidades do movimentar-se.

Realizamos dois recortes em dois vídeos, resultado das filmagens do jogo transmitido (Brasil x Equador, RJ, 17/10/2007) e do espetáculo Lunário Perpétuo (Recife/PE, 2003). O corte é uma técnica cinematográfica que permite a montagem, e esta, por sua vez, tem mais a ver com o tempo do que com o espaço. Por isso, a ginga, no drible e na mandinga, foi vista em "pedaços de uma cena em rápida sucessão, montando um painel de mosaicos que dá a impressão de muitas coisas acontecendo ao mesmo tempo", esclarece Pignatari (1984, 
p.12). De modo que analisamos a linguagem em corte, nesses dois episódios, num drible de futebol e numa mandinga na dança.

Para essa linguagem em corte, tomamos dois episódios espetaculares, de reconhecimento nacional pela plasticidade brasileira, no futebol e na dança. No futebol, Robson de Souza (Robinho) e na dança, Antonio Nóbrega; nomes do mundo do espetáculo, capazes de, através dos movimentos de seus corpos, manterem o público atento e também em movimento. A ginga nos dribles de Robinho nos estádios rivaliza com a ginga do brincante Antônio Nóbrega em suas apresentações que contam, ainda, com suas habilidades como cantor, compositor e instrumentista.

A análise transcorreu pela configuração corporal em dois gestos, no futebol, o drible pedalada e na dança, a mandinga. A metodologia utilizada foi a labanalise ou Laban Movement Analysis (LMA), que permite perceber o modo como o corpo utiliza o espaço e o tempo. Os movimentos são descritos com ênfase em seus aspectos qualitativos ou expressivos, ou seja, como cada uma das ações é executada segundo quatro fatores: fluxo, espaço, peso e tempo. O fluxo se refere à tensão muscular usada para deixar fluir o movimento (livre ou controlado). O espaço diz da atenção do indivíduo ao ambiente ao mover-se (direto ou indireto/multifoco). O peso corresponde a mudanças na força usada pelo corpo ao mover-se (forte ou leve). E, por fim, o tempo que indica a variação na velocidade do movimento (rápida ou lenta).

Nesse sentido, pela forma de descrição e registro do movimento, é possível perceberse questões como a necessidade de mover-se e a atitude interna que precede ou impulsiona a ação em si. Pela LMA não se descreve apenas os padrões de movimento, em seus percursos e ritmos, mas investiga-se sua atmosfera, os sentimentos e intenções que estão movendo-os. Assim como Costa, Gomes-da-Silva e Schulze (2012) pesquisaram a atitude do professor analisando seu andar, também nós investigamos a atitude do gingado brasileiro, impresso nas mandingas e dribles.

\section{$3 \quad$ Resultados}

\subsection{Antônio Nóbrega (Recife, 1952): análise da mandinga no espetáculo Lúnário}

\section{Perpétuo}


Antonio Carlos Nóbrega é um artista multi-instrumentista que pertenceu à Orquestra de Câmara da Paraíba e à Orquestra Sinfônica do Recife. Mais tarde, no início dos anos 1970, integrou o Movimento Armorial, partindo de referências ibéricas e mouriscas presentes no Nordeste, para criar uma música única. Transferido para São Paulo, Nóbrega continuou sua carreira solo, sempre unindo os vários instrumentos que toca à dança, ao teatro e a tudo que se refere à cultura popular pernambucana (WOLNEY, 2010).

Estudioso e apaixonado pela manifestação cultural popular brasileira, Nóbrega é um forte exemplo de identidade regional/nacional, possivelmente o artista brasileiro mais completo (instrumentista, dançarino, compositor, ator e cantor e coreógrafo). Gravou vários CDs e DVDs, todos voltados ao ritmo predominantemente brasileiro, apresentando arranjos próprios em seus espetáculos, que são bastante concorridos pelo público conhecedor de sua arte.

O espetáculo Lunário Perpétuo, com turnê em todo Brasil, foi filmado, por ocasião do seu lançamento, no teatro da UFPE em Recife, em 2002. A produção em DVD (90 min, 2003) contou com a direção de Walter Carvalho. Nóbrega denominou Lunário Perpétuo ao seu espetáculo, por representar uma espécie de compêndio dos seus 30 anos de carreira, reunindo toques, cantos, instrumentais, danças e emboladas. Um almanaque semelhante ao "Lunário", que era um livro espanhol, traduzido para o português no século XVIII, que esteve em voga durante muito tempo no sertão nordestino, que continha informações gerais: santos do dia, efemeridades, fases da lua para o plantio, receitas medicinais caseiras e conselhos úteis mil.

Antônio Nóbrega estava com aproximadamente 50 anos quando gravou o DVD Lunário Perpétuo, numa habilidade criativa em harmonizar o universo dos repertórios populares, com os emblemas e símbolos europeus da Idade Média, que estão na base da formação cultural dos brasileiros. Nóbrega apresenta-se como um brincante, cuja arte flui das descobertas de pesquisas, de profissionalização de instrumentalistas, fincando as bases de uma linguagem substantivamente nova, produzindo um laço cada vez mais forte entre o artista, sua obra, e seus públicos. O espetáculo Lunário Perpétuo ensina a amar a terra e o que dela procede, em seus ritmos, musicalidade e genialidade.

\begin{tabular}{|l|l|l}
\hline Fotograma & Quadro (Frame) & Observações \\
\hline
\end{tabular}




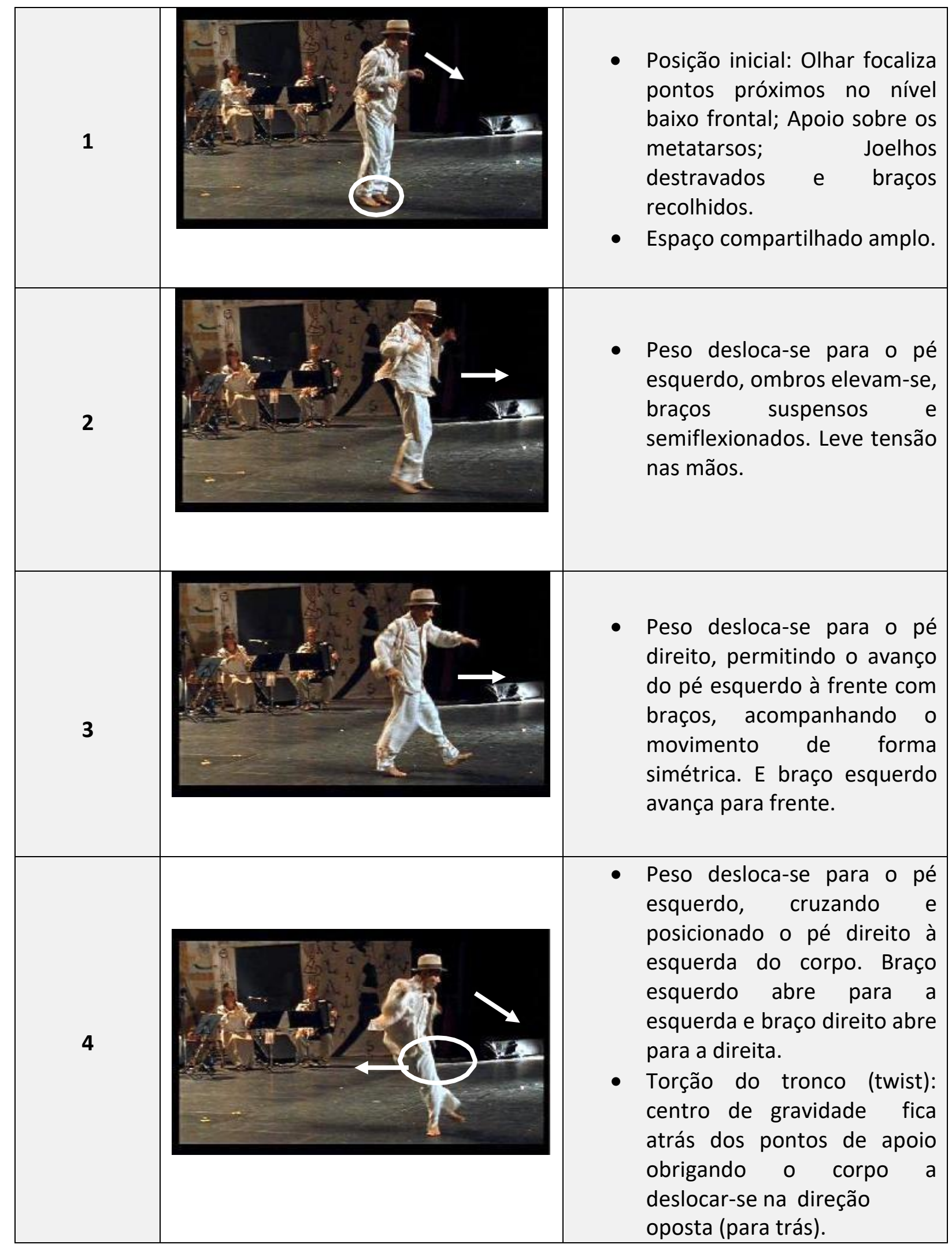




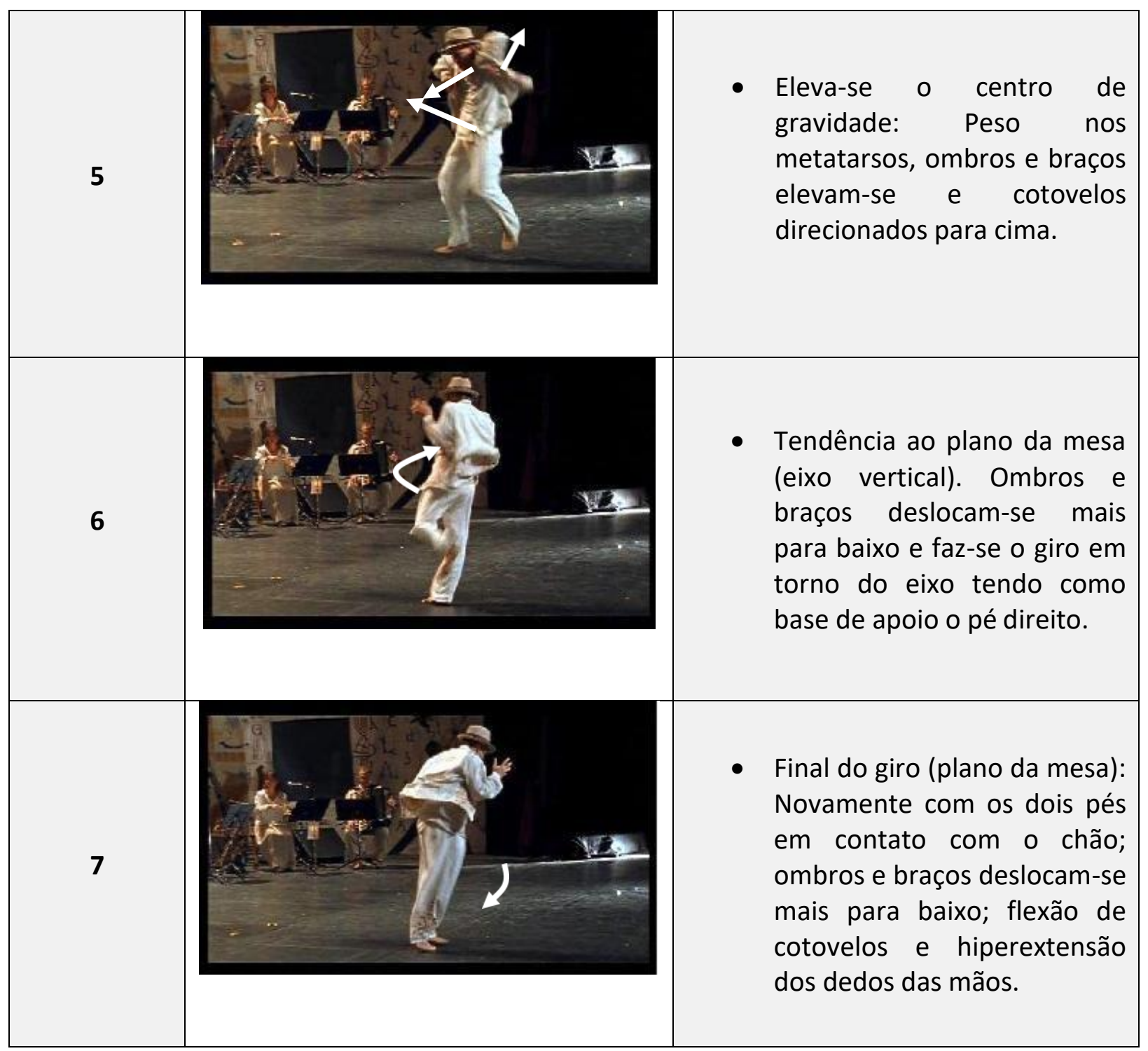

Fonte: <http://youtu.be/gaZvdxKdau0>

Quadro 1 - Mandinga dançada por Antônio Nóbrega em Lunário Perpétuo

Os fatores do movimento, pela LMA, são quatro contextualizados pelo corpo do praticante. Daí apresentarmos um pouco da motilidade do cantor-brincante em seu espetáculo e os fatores de peso, espaço, fluxo e tempo.

a) Fator Espaço: Os movimentos na sequência observada estavam centralizados na kinesfera (espaço pessoal que cerca cada um, até onde pode alcançar- NEWLOVE, 2004) delimitada essencialmente pelo olhar dirigido para a diagonal baixa. O foco estava dirigido para a forma como os pés estavam em contato com o piso dando a sensação que o tronco e os braços apenas acompanhavam ou contrabalançavam os movimentos. 
b) Fator Tempo: súbito e rítmico com pequenas variações sincopadas. Repetição rítmica da sequência por algumas vezes.

c) Fator Peso: forte com movimentos partindo do centro para as extremidades com acento para fora. Impulso nos pés para cima com apoio nos metatarsos.

d) Fator Fluxo: controlado, com tensão muscular nos artelhos, abdômen e dedos das mãos para realização dos movimentos.

Essa mandinga apresentada por Nóbrega foi realizada com movimentos súbitos, rítmicos e sincopados; parece ter influência do frevo, do reisado e do maracatu pernambucanos. A alegria e fluência com que realiza os passos da dança demonstram o grau de intimidade que possui com os padrões de movimento interpretados. Essa intimidade estende-se à relação com o público quando, ao invés de enfrentar ou apresentar-se para a plateia, parece convidá-la a dançar com ele. Isso acontece essencialmente através da direção do olhar que, dirigido para a diagonal baixa, dirige os olhares para seu corpo ao invés de levantar os olhos na direção do público ou acima dele, quando obrigaria os olhares a dividir a atenção entre seus movimentos e seu rosto. O apoio nos metatarsos demonstra uma disponibilidade para sair do chão e avançar.

Nóbrega não faz uso de movimentos amplos, dedica-se a dominar seu gestual dentro de uma kinesfera mais próxima. Assim, apesar de dispor de um amplo espaço de palco que, por vezes, percorre traçando um caminho circular, especificamente na sequência analisada percorre uma diagonal do centro-trás para a esquerda-frente, retornando em seguida. Isso também sugere um convite ou provocação para que a plateia dance com ele. Os acentos definidos ao final de muitos movimentos dos pés, como se chutasse o ar juntamente com o foco baixo não deixa de ser um link entre a performance de um jogador de futebol e a sua própria.

\subsection{Robinho (Nasc. São Paulo, 1984): análise do drible Você vai pra lá que eu vou pra cá}

Assim como muitos outros jogadores brasileiros, Robinho iniciou sua prática na modalidade futebol de salão. Morador de área carente, no litoral de São Paulo, jogador desde os 6 anos, conhecido quando criança como neguinho do cemi, porque entre um e outro batebola, guardava carros em frente ao cemitério do bairro do Biratu. Ao ser descoberto por um

olheiro (caça-talentos) o ainda menino aprendera mais sobre o controle 
de bola. Alguns anos depois, era titular do time de futsal do Santos Futebol Clube, clube de futebol que o lançou e o tornou ícone do esporte. Reconhecido como o driblador, enganador dos adversários, o atacante atraiu a atenção da mídia especializada, tal como o interesse dos

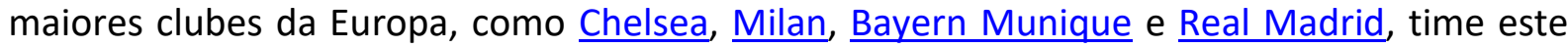
com o qual assinou contrato, rendendo alguns milhões de dólares ao seu clube brasileiro (GLOBO ESPORTE, 2010).

\begin{tabular}{|c|c|c|}
\hline Fotograma & Quadro (Frame) & Observações \\
\hline 1 & & $\begin{array}{l}\text { - Robinho: focaliza o olhar no } \\
\text { nível baixo, na direção da } \\
\text { cintura do adversário; Joelhos } \\
\text { destravados e afastados entre } \\
\text { si, proporcionando maior } \\
\text { equilíbrio do tronco; Braços } \\
\text { separados do corpo e } \\
\text { semiflexionados; palma da } \\
\text { mão voltada para trás. Espaço } \\
\text { compartilhado amplo. } \\
\text { - Adversário plantado em } \\
\text { prontidão (foco na bola). }\end{array}$ \\
\hline 2 & & $\begin{array}{l}\text { - Robinho: Peso desloca-se para } \\
\text { o pé esquerdo; Perna direita } \\
\text { realiza gestual para iludir } \\
\text { adversário (passando em } \\
\text { círculo sobre a bola finta), o } \\
\text { que se dá por } 2 x \text {; Braço direito } \\
\text { elevado, compensando a ação } \\
\text { da perna direita; Centro de } \\
\text { gravidade em equilíbrio, } \\
\text { levemente puxado para trás } \\
\text { para defender-se de um } \\
\text { possível avanço do adversário. } \\
\text { Adversário continua imóvel, } \\
\text { estável com olhar focado na } \\
\text { bola. }\end{array}$ \\
\hline
\end{tabular}




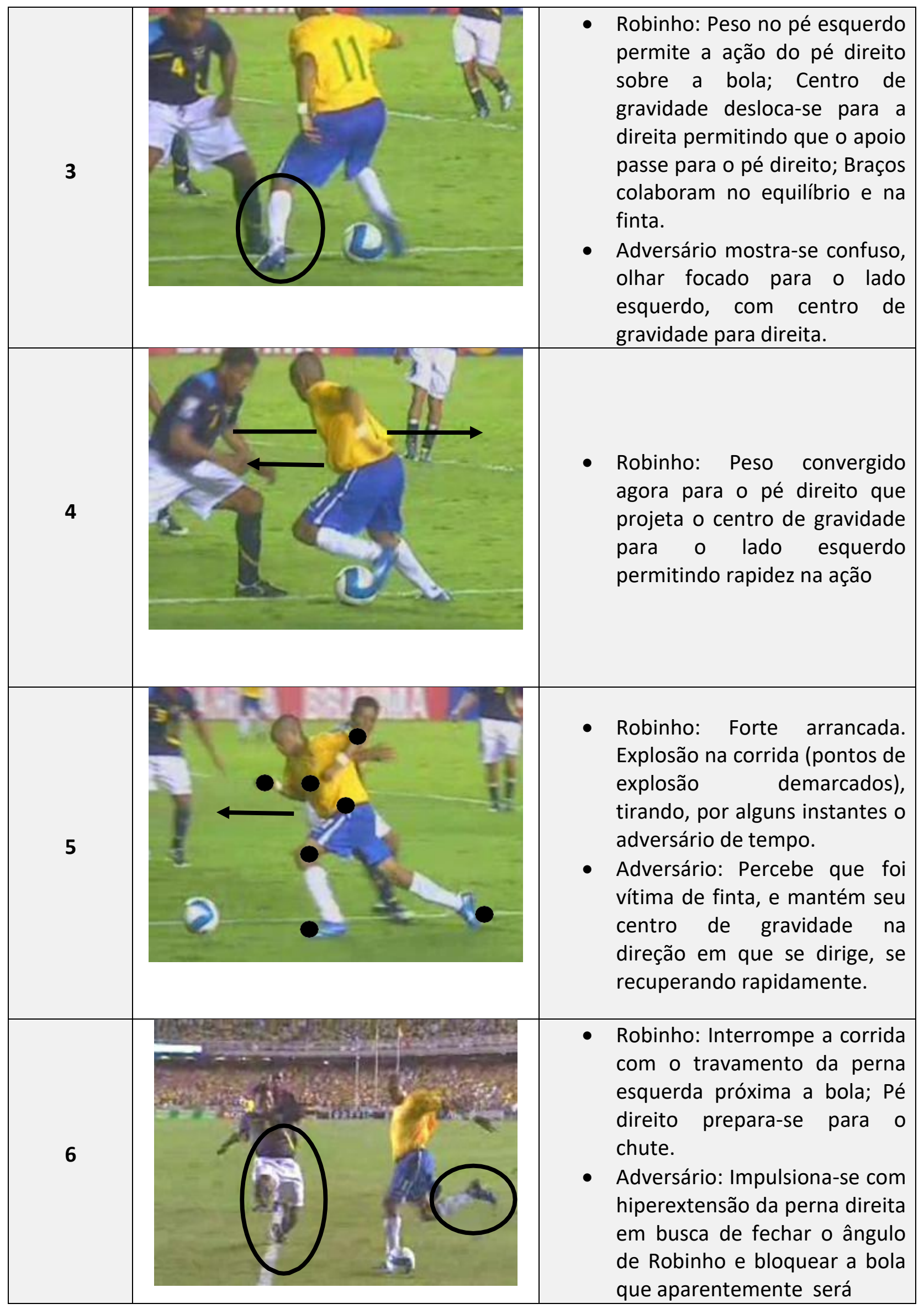




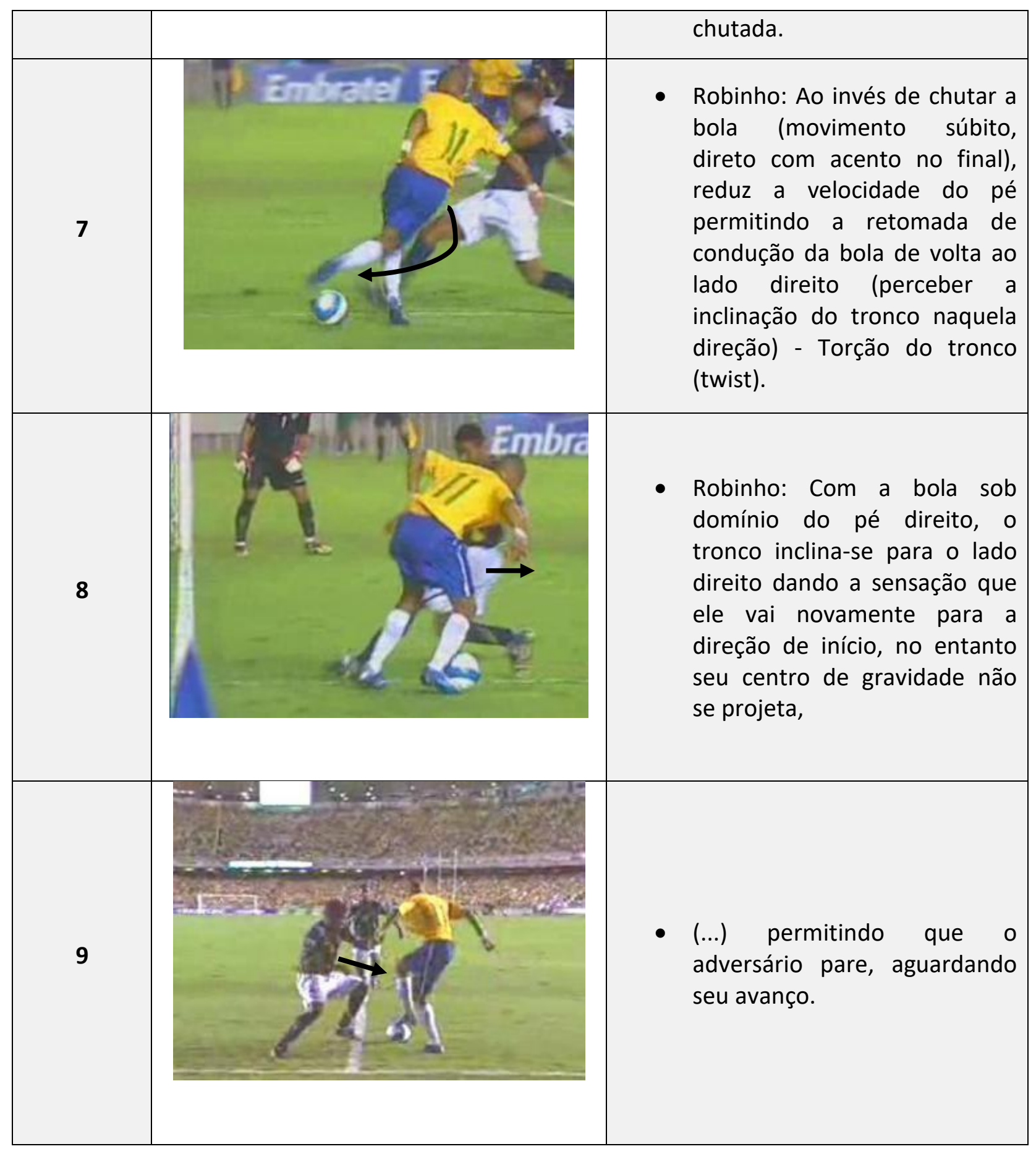




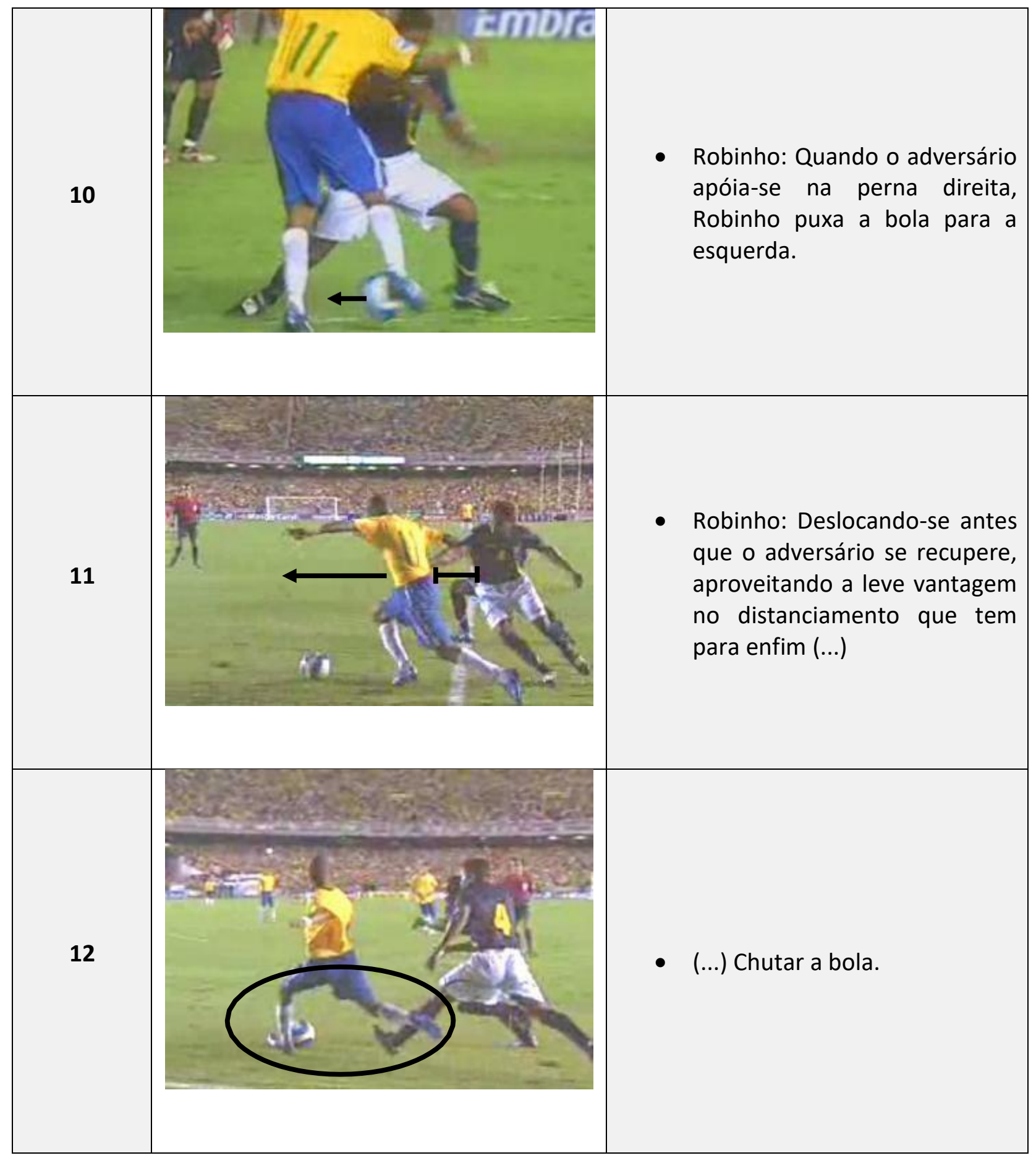

Quadro 2 - Drible realizado por Robinho no jogo Brasil x Equador, nas eliminatórias da Copa 2010, Maracanã/RJ, em 17/10/2007

F onte: $<$ http://youtu.be/W5rvr54nyKs $>$

Robinho estava com 23 anos quando participou do jogo contra o Equador no estádio do Maracanã, em 17 outubro de 2007. Esse drible foi objeto de discussão nos comentários esportivos da semana que se seguiu. Ao ser entrevistado denominou seu drible como sendo: 
você vai pra lá que eu vou pra cá. Os movimentos desse drible podem ser analisados pelos fatores de movimento.

a) Fator Espaço: a sequência de movimentos esteve delimitada em sua kinesfera próxima, com certo deslocamento, mas dirigida pelo olhar focado na diagonal baixa: cintura do adversário e bola entre os pés;

b) Fator Tempo: súbito e rítmico, com pequenas variações sincopadas. Algumas repetições gestuais do pé direito por sobre a bola, circundando-a, numa sequência rápida com o fim de ludibriar o adversário;

c) Fator Peso: forte com movimentos partindo do centro para as extremidades com acento para fora. Impulso nos pés para cima com apoio nos metatarsos em alguns momentos;

d) Fator Fluxo: controlado com movimentos de paradas bruscas e explosões em arrancadas e chutes.

Os movimentos são rápidos, diretos, leves e controlados. A leveza somada à destreza das ações demonstram o grau de intimidade que o jogador possui com a condução da bola. Essa intimidade transparece na relação comunicativa com o adversário, provocando-o a tomar a bola. Na medida em que o adversário responde às ações da finta, outra ação ludibriadora acontece, escapando da marcação. Isso acontece essencialmente por meio de sinais gestuais emitidos: direção do olhar para a diagonal baixa, inclinações do tronco para certa direção, dos apoios nos pés e movimentos de pernas livres por sobre a bola. Ele faz uso de movimentos curtos e arrancadas aparentemente amplas para incrementar seu domínio espacial em uma área tão grande como o campo de futebol. Percorre um caminho reto até encontrar o adversário quando alterna a trajetória entre direita e esquerda até que logra retomar a linha reta para passar a bola após ultrapassar o adversário. $\mathrm{O}$ acento definido ao final de muitos movimentos dos pés tem a função de conduzir a bola.

\section{Discussão}

A mandinga de Nóbrega e o drible de Robinho são realizações próprias do gingado brasileiro, um molejo de cintura e explosão nas pernas e pontas dos pés. Pela LMA, como linguagem de mapeamento corporal baseada em suas quatro categorias, apostamos que o impulso que move as duas ações espetaculares possui a mesma natureza, portanto, sinaliza 
a mesma atitude adotada, tanto pelo jogador quanto pelo cantor-brincante. As atmosferas que os precursores carregam em seus movimentos pelo espaço estão tingidas pelos mesmos sentimentos e ideias, pelo mesmo impulso. Uma qualidade expressiva condensada ou também denominada por Fernandes (2005, p. 43) como "Atitude Lutante", que quer dizer uma certa ordem na disposição dos quatro fatores.

Ambos relacionam-se com o espaço a partir de um olhar focado, para baixo ou para diagonal-baixo, declarando atenção na ação. Os brincantes, no futebol ou na dança, estão totalmente inteiros no que estão fazendo, estão centrados, focados. Quanto ao peso, em ambos, o esforço é forte, no sentido de flexível nas mudanças da força usada pelo corpo. Em ambos, potência e vigor dizem de um peso ativo. A leveza dos gestos não significa relaxamento, mas força de mobilidade. O tempo é de um fraseado expressivo, Robinho e Nóbrega gingam num estado rítmico, dinâmico, rapidez e paradas bruscas. De modo que o fluxo não é contínuo, mas controlado, cada gesto é muito bem delimitado, cuidado, pensado. Daí a conclusão da atitude lutante, porque o gingado apresentado possui um fluxo contido, um espaço direto, um peso forte e um tempo acelerado.

Esse fraseado expressivo, ou essa qualidade de atitude, pode ser confirmado pela teoria Texto do Futebol de Silveira e Silva (2010), ao afirmarem que um encadeamento de gestos futebolísticos forma um enunciado, ou seja, os gestos dos jogadores (morfologia), seus significados (semântica) e sua organização (sintaxe), constrói um discurso ou texto. Ao pensarmos no drible ou na mandinga como texto, nos aproximamos de Pasolini (1971) para tipificar a singularidade desse enunciado. Pasolini (1971) propôs classificar o texto futebolístico como futebol-prosa, baseado no encadeamento lógico de jogadas, e futebolpoesia, quando há preponderância de jogadas imponderáveis, que destroem e reorganizam o jogo. Desse modo, a finta no futebol ou a mandinga na dança, pertencem ao texto poético, porque são expressões individuais de inegável talento e beleza plástica, ao tempo que são fulgurantes e eficazes.

Enquanto Robinho tem seu foco concentrado na bola e no adversário, Nóbrega se concentra em pontos no espaço e na música. A plateia do show, assim como o adversário, é estímulo definitivo que gera energia e qualidade de expressão para ambos. Robinho e Nóbrega (jogador e brincante) movem-se com atenção ao ambiente, atentos a mudanças do ambiente que possam indicar-Ihes algo, som da música ou movimento do adversário. Isso 
está posto devido o possível treino de ambos em focarem a visão no espaço de atuação, palco e campo.

Em termos do fator tempo, as sequências de movimento selecionadas trazem um passo em comum, conhecido no futebol como toque de letra ou pedalada, e na dança como

cruzado de perna. Trata-se do movimento de cruzar uma perna por trás da outra que é o ponto de apoio levando a uma torção do tronco. Robinho (ver fotograma 7) utilizou-o para fintar o adversário e Nóbrega (ver fotograma 4) a utilizou para brincar com seu aparente partner (parceiro) imaginário. Enquanto Robinho deixa de acentuar o final do movimento para deslocar-se de volta à direção de onde vinha, Nóbrega acentua em tempo súbito, marcando o final de um avanço e o retorno à mesma direção de onde vinha. Esse cruzado indica uma variação na velocidade de movimento, ambos os brincantes saem de um tempo desacelerado para uma aceleração brusca, ao realizarem o gesto. Essa mudança na qualidade do tempo, variação quantitativa de velocidade, dá ênfase na qualidade expressiva,

dilatando o tempo na ação. Ou seja, esse gingado ao relacionar-se com o quando do movimento, põe em evidência a intuição do jogador e sua rápida decisão diante do contexto.

A ginga existente nos movimentos analisados foi possível não só porque Robinho ou Nóbrega são atletas e artistas, respectivamente. Mas, supomos, pelas experiências corporais que esses sujeitos viveram no território cultural brasileiro, seja Recife/PE ou São Paulo/SP, com o brincar na rua ou o aprender música em escolas. Tanto o Robinho, reconhecidamente como brincalhão, quanto o Tonheta, personagem de Nóbrega, um misto de palhaço e vagabundo, são tipos populares que povoam as ruas e praças do Brasil. Nesse ponto é que esta pesquisa nos sugere o desdobramento educativo, a partir de seu viés cultural.

\section{$5 \quad$ Considerações Educativas}

Por meio dos movimentos analisados, pudemos perceber que a ginga que se faz presente no futebol ou na dança é constituída por um mosaico da estética corporal do brasileiro, configurada numa horizontalidade de fluidez e graça, própria da concepção de cultura da festa do brasileiro. Essa estética da ginga brasileira desdobra-se em pelo menos 
duas implicações educativas: o gingado brasileiro impõe a necessidade de uma educação sensorial e multiétnica.

Primeiro, pela LMA, vimos que a ginga brasileira está caracterizada por uma atitude lutante, ou seja, que esses movimentos tão próprios da cultura e valorizados nacionalmente, dizem não de uma malandragem para a preguiça, desleixo ou improdutividade. Pelo contrário, o fluxo contido, o espaço direto, o peso forte e o tempo acelerado revelam uma qualidade dinâmica, aberta para a mudança, inteligente para tomada de decisões rápidas e eficazes em seus resultados. Sendo assim, é preciso pensar uma educação que assuma a ginga como uma diretriz pedagógica para tratar os conhecimentos escolares, ao tomar o movimento como linguagem capaz de promover e multiplicar sentidos.

A começar pela valorização do corpo, ou melhor, da corporeidade dos educandos. Não se aprende, pelo menos no Brasil, sem considerar o movimento dos alunos. Uma escola que não inclui o movimento como motor da aprendizagem ainda não é brasileira, no sentido da ginga. Tem de haver uma "pedagogia da ressurreição do corpo" (GOMES-DA-SILVA, 2011b, p. 123), aquela que afirme a centralidade da percepção corporal e a primazia da experiência vivida na constituição de toda e qualquer aprendizagem. Movimento como conexão entre a experiência visível e a invisível, o pensamento invisível encarnado na visibilidade do movimento. Movimento não é expressão de pensamento ou sentimento, mas ele é o próprio pensamento e sentimento. Ele não é representação de algo, mas o próprio modo proposicional de representação. Uma escola em movimento, tanto do ponto de vista da mobilidade corporal, quanto da mobilidade de conhecimentos, estratégias e espaços educativos.

Quando afirmamos mobilidade corporal estamos pensando, especificamente, numa educação sensorial, porque estamos convencidos, a partir de inúmeras pesquisas, a exemplo de expressividade e sensorialidade (FIGUEIREDO JR; GOMES-DA-SILVA, 2011), que é por meio da exploração sensorial que se desenvolvem, gradualmente, as qualidades expressivas. E é a qualidade expressiva, na perspectiva labaniana, que provoca a evolução da atenção (espaço direto), intenção (peso forte) e decisão (tempo acelerado). Fatores encontrados na ginga brasileira, expressividade cuja ênfase abrange duas vertentes: descobrir e defender. Utilizamos a sensorialidade para descobrir o mundo, no momento em que nos relacionamos com o meio, mudando a percepção para adquirir maior interação. 
Bem como, de igual necessidade, lançamos mão da sensorialidade para defesa do mundo, para nos proteger do meio, quando este ameaça aniquilamento, então, evitamos a mudança perceptiva e consequente relacionamento. De modo que a sensorialidade e expressividade ocupariam o centro de ensino em todos os componentes curriculares.

Segunda implicação educativa da estética do gingado brasileiro: educação multicultural. A descrição e análise dos gingados de Robinho e de Antônio Nóbrega, mais do que tudo arte performática, nos fez perceber um padrão de movimento com profundas raízes no universo popular. Adotando uma perspectiva mais antropológica, a ginga configura-se como reflexo de uma nação plurificada ou invés de unificada. Nas palavras de Ribeiro (1995), o Brasil é resultante da fusão desses milhões de gente desencontrada. Fusão genética, uma vez que a mestiçagem, aqui, sempre se fez sem freios e sem nenhuma noção que fosse crime ou pecado. Fusão também espiritual, pela confluência que aqui se deu dos patrimônios culturais de nossas diversas matrizes. Tudo isso nos plasmou como um povo mestiço na carne e no espírito. Eis a justificativa da clássica afirmativa de Freyre (1947, p.113), quando diz que "todo brasileiro, mesmo o alvo, de cabelo louro, traz na alma, quando não na alma e no corpo, a sombra, ou pelo menos a pinta, do indígena e/ou do negro".

Compreendemos que o gingado de todos nós, brasileiros, é fruto da mestiçagem. É propriedade de um povo, que é produto da confluência de várias culturas e povos. E a contribuição das diferenças é que de fato proporciona a originalidade desta cultura (MUNANGA, 1999). Essa autenticidade do mestiço, ao contrário de pensar a pureza como unidade, o que nos une, como povo tipicamente misturado. Nossa unidade, por sermos desde sempre mestiços, é sermos multiétnicos, multiculturais, com pluralidade de vozes e expressões. E, nessa multiculturalidade, inventamos e reinventamos maneiras diversificadas de estarmos no mundo. E a ginga é expressão contundente dessa miscigenação.

$\mathrm{O}$ drible e a mandinga analisados expressam essa conjuntura cultural de diferentes sentimentos e pertencimentos. Isso reforça a prerrogativa de que a ação funcional de ginga é uma marca expressiva, peculiar à pluralidade identitária gestual. Desse modo, a ginga é transindividual do sujeito, portanto, enuncia um modo de agir comunicativo, permeado de expressão de vitalidade, com ações risonhas e zombeteiras, capazes de surpreender e produzir alegria. Semelhante ao que Lévi-Strauss (1970, p. 42) denominou de "mística 
operativa", a ginga brasileira articula o simbólico, presente no seu universo de representações, e o orgânico, presente na conformação das forças físicas e anatomofisiológicas do brasileiro.

Nesse sentido, uma educação que considere a ginga do brasileiro valorizará o espaço de confluência das diversas culturas. A cultura popular terá um lugar central, porque é nela que estão plasmadas as raízes do universo simbólico do povo brasileiro. A dança e o futebol terão prioridade sobre o aprender. No Brasil se deveria aprender por meio da dança e do futebol, assim, os brasileiros certamente aprenderiam melhor, diferente de ficarem cada vez mais aprisionados por milhares de horas numa carteira. Uma educação multicultural aposta na alegria de aprender dançando, driblando, num ritmo de aprendizagem que seja significativa para cada uma das diferentes raças, gêneros, visão de mundo, condições socioeconómicas, religiosas. Sendo assim, impõe-se uma educação cujas propostas de práticas curriculares problematizem a construção das diferenças, a relação entre pluralidade cultural e poder, a diversidade de valores... Uma proposta curricular que dilua as fronteiras dos universos culturais distintos e que garanta uma formação de consciência crítica quanto às desigualdades culturais e exclusão social.

\section{Referências}

CASCUDO, L. da C. História dos nossos gestos: uma pesquisa na mímica do Brasil. São Paulo: Melhoramentos, 1976.

COSTA, S.B.; GOMES-DA-SILVA, P.N.; SHULZE, G. A linguagem expressiva do andar. In: CATTUZZO, M.T.; CAMINHA, I.O. (Orgs.). Fazer e pensar ciência em educação física - livro 1. Ed. Universitária UFPB, 2012.

FERNANDES, C. O corpo em movimento: o sistema Laban/Bartenieff na formação e pesquisa em artes cênicas. 2ed. São Paulo: Annablume, 2005.

FIGUEIREDO JR. J.M.; GOMES-DA-SILVA, P.N. Expressividade e sensorialidade. Rev. Ativ. Fís. e Sau., Pelotas/RS, v.16, n.2, p.172-176, 2011.

FREYRE, G. Interpretação do Brasil. Rio de Janeiro: José Olympio, 1947 (Coleção Documentos Brasileiros. no 56).

FRISSELLI, A.; MANTOVANI, M. Futebol: Teoria e Prática. São Paulo: Phorte, 1999.

GIL, J. Movimento total. São Paulo: Iluminuras, 2009. 
GLOBO ESPORTE. Portal Globo Mídias. Disponível em: <http://globoesporte.globo.com/>. Acesso em: 6 set. 2013.

GOMES-DA-SILVA, P.N. Corporeidade do movimento: por uma análise existencial das práticas corporais. In: HERMIDA, J.F.; ZOBOLI, F. (Orgs.). Corporeidade e educação. João Pessoa: Ed. Univ. UFPB, 2012. p.139-174.

GOMES-DA-SILVA, P.N. 0 jogo da cultura e a cultura do jogo: por uma semiótica da corporeidade. João Pessoa: Ed. Universitária UFPB, 2011a.

GOMES-DA-SILVA, P.N. Pedagogia da ressurreição do corpo: muito além do medo da morte. In: GOMES, E.S.; POSSEBON, F. O evangelho apócrifo de Pedro. João Pessoa: Ed. Univ., UFPB, 2011b. p.123-149.

GOMES-DA-SILVA, P.N. GOMES, E.S.L. Malhação: corpo juvenil e imaginário pós-moderno. João Pessoa: Ed. Universitária - UFPB, 2010.

LÉVIS-STRAUSS, C. A. As estruturas elementares do parentesco. Petrópolis: Vozes, 1976.

MONTES, M.L. Entre o arcaico e o pós-moderno: heranças barrocas e a cultura da festa na construção da identidade brasileira. Rev. Sexta-Feira, São Paulo/SP, v.2, n.2, p.12-26, abr. 1998.

MUNANGA, K. Rediscutindo a Mestiçagem no Brasil: Identidade nacional Versus Identidade Negra. Petrópolis: Vozes, 1999.

NEWLOVE, J.; DALBY, J. Laban for all. London: Routhledge, 2004.

PASOLINI, P.P. O gol fatal. [1971]. Disponível em: <http://bit.ly/fLR6Ta>. Acesso em: 12 out. 2010.

PIGNATARI, D. Signagem da televisão. São Paulo: Brasiliense, 1984.

RIBEIRO, D. O Povo Brasileiro: a formação e o sentido do Brasil. São Paulo: Companhia das Letras, 1995.

SILVEIRA, M.T.; SILVA, A.R. Lendo o jogo: o futebol enquanto linguagem. CONGRESSO BRASILEIRO DE CIÊNCIAS DA COMUNICAÇÃO, 33, 2010, Caxias do Sul. Anais do Congresso Brasileiro de Ciências da Comunicação, Caxias do Sul, Sociedade Brasileira de Estudos Interdisciplinares da Comunicação (Intercom), 2010. p.1-15, disponível em mídia CD.

SODRÉ, M. Mestre Bimba: corpo de mandinga. Rio de Janeiro: Manati, 2002.

TOLEDO, R.P. Contribuições para uma etiologia do pontapé. Revista Veja, São Paulo, ano31, n.22, p.174, 3 jun, 1998. 
WOLNEY U. (Ed.). Antônio Nóbrega: entrevista. Revista da UFG, Goiânia, ano XII, no 8, p.126-

134, jul. 2010. Disponível em: <http://www.proec.ufg.br/revista_ufg/Revista UFG - 2010>. Acesso em: 1 fev. 2011.

Enviado em Abril/2013

Aprovado em Abril/2014 